of patients with reduced WP at month 12 remained high $(74.1 \%$; graph 1$)$. We observed a moderate positive significant correlation between presenteeism and absenteeism $\left(r_{\text {Mo12 }}=0.446 ; p<0.001\right)$. Patients with no restrictions on WP showed a significantly greater decrease in mean DAS28 from 3.7 (SD 1.15) at baseline to 1.9 (SD 0.61) at month 12 as compared to patients with restrictions (mean DAS28: 4.4 (SD 1.04) at baseline to 2.7 (SD 1.15) at month 12; $p<0.001$ ). Results from univariate and logistic regression analyses revealed high functional capacity and low depression score at baseline as major contributing factors for unimpaired WP (Table 1)

Table 1. Baseline predictors of work participation ${ }^{1}$ at month 12

\begin{tabular}{|c|c|c|}
\hline Predictors (independent variables) & $\begin{array}{c}\text { Univariate analysis }{ }^{2}: \\
\text { p-values }\end{array}$ & $\begin{array}{l}\text { Multivariate analysis } \\
\text { Odds Ratios, } p \text {-values }\end{array}$ \\
\hline gender & $0.117^{+}$ & OR: $0.412 ; p=0.113$ \\
\hline age & $0.010^{\star+}$ & OR:0.951; $p=0.071$ \\
\hline school graduation & $0.150^{+}$ & \\
\hline professional degree & 0.739 & \\
\hline duration of complaints & $0.127^{+}$ & \\
\hline $\begin{array}{l}\text { therapy group (starters vs. escalation/ } \\
\text { change) }\end{array}$ & $0.004^{\star+}$ & \\
\hline DAS-28(CRP) & $0.001^{*}$ & \\
\hline CRP & 0.906 & \\
\hline tender joints & $0.004^{*}$ & \\
\hline swollen joints & $0.021^{*}$ & \\
\hline disease activity (VAS) & $0.003^{\star+}$ & OR: $0.827 ; p=0.086$ \\
\hline subjective disease activity (RADAI) & $<0.001^{*}$ & \\
\hline disease burden (RAID) & $<0.001^{*}$ & \\
\hline functional capacity (FFbH) & $<0.001^{\star+}$ & OR: $1.477 ; p=0.031^{*}$ \\
\hline fatigue (VAS) & $<0.001^{\star+}$ & \\
\hline depression (PHQ-9) & $<0.001^{\star+}$ & OR: $0.876 ; p=0.035^{\star}$ \\
\hline working time model (full vs. part-time) & 0.498 & \\
\hline physical work load & 0.427 & \\
\hline
\end{tabular}

${ }^{1}$ dependant variable: $0=$ reduced WP (not working/ absenteeism/ presenteeism ( $\left.\geq 2\right)$ ); $1=$ full WP (working without absenteeism/ presenteeism $(\geq 2))^{2}$ according to applicability chi-square test, $t$-test for independent variables, Mann-Whitney- $U$ test ${ }^{3}$ binary logistic regression analysis, stepwise-backward procedure ${ }^{+}$included into logistic regression model ${ }^{*}$ significance level: $\mathrm{p}<0.05$

Graph 1: Work participation during study period

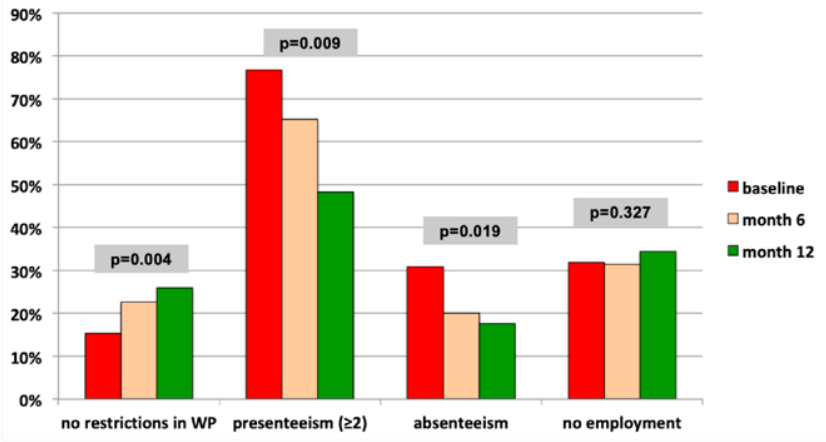

Conclusion: Despite T2T and high DAS28 remission, we observed persistent limitations in WP. Impaired WP was associated with increased disease activity but logistic regression revealed a significant influence of depression and functional capacity. Our data underscore the multifactorial causes of impaired WP, which should be targeted by vocational rehabilitation.

Disclosure of Interests: Sara Eileen Meyer: None declared, Juliana Rachel Hoeper: None declared, Torsten Witte: None declared, Kirsten Hoeper Speakers bureau: She has received consultancy and speaker honoraria from Abbvie, Chugai, Gilead, Lilly, Novartis, Sandoz Hexal and Sanofi., Dirk Meyer-Olson Speakers bureau: He has received consultancy and speaker honoraria from Abbvie, Amgen, Berlin Chemie, Bristol Myers Squibb, Cellgene, Chugai, Fresenius Kabi, GSK, Jansen Cilag, Lilly, Medac, Merck Sharp \& Dome, Mylan, Novartis, Pfizer, Sandoz Hexal, Sanofi and UCB.

DOI: 10.1136/annrheumdis-2021-eular.1250

\section{OP0261-HPR PERCEIVED CHALLENGES AT WORK AND NEED FOR SUPPORT AMONG PEOPLE WITH INFLAMMATORY ARTHRITIS}

C. M. T. Madsen ${ }^{1,2}$, J. Reffstrup Christensen ${ }^{3,4}$, A. Bremander $^{1,2,5}$, J. Primdahl ${ }^{1,2,6} .^{1}$ Danish Hospital for Rheumatic Diseases, University Hospital of Southern Denmark, Sønderborg, Denmark; ${ }^{2}$ Department of Regional Health Research, University of Southern Denmark, Odense, Denmark; ${ }^{3}$ Research Unit of General Practice, Department of Public Health, University of Southern
Denmark, Odense, Denmark; ${ }^{4}$ Research Unit of User Perspectives, Department of Public Health, University of Southern Denmark, Odense, Denmark; ${ }^{5}$ Section of Rheumatology, Department of Clinical Sciences Lund, Lund University, Lund, Sweden; ${ }^{6}$ Hospital of Southern Jutland, University Hospital of Southern Denmark, Aabenraa, Denmark

Background: People with inflammatory arthritis (IA), i.e. rheumatoid arthritis, psoriatic arthritis and axial spondyloarthritis, often experience low work ability and up to $38 \%$ lose their job during the first years after being diagnosed with IA (1). As a result, people with IA have a higher risk of job loss and permanent exclusion from the labor market than people without IA $(1,2)$. Work-related rehabilitation is complex and encompass a variety of interventions which aim to reduce barriers to maintain work and improve work ability. Unfortunately, positive results from work-related rehabilitation is scarce (3), why a better understanding of the challenges people at risk for job loss experience is needed to develop relevant interventions.

Objectives: To explore perceived challenges and need for support to remain at work among people with IA who are at risk of job loss.

Methods: A qualitative explorative design based on a hermeneutic approach was applied. Outpatients with IA who considered themselves at risk for long-term job loss, were recruited at the Danish Hospital for Rheumatic Diseases. An interview guide was developed based on earlier results from a systematic review and qualitative studies in close cooperation with three patient research partners. Individual semi-structured interviews were performed from December 2019 to May 2020.

Results: Eleven women and four men with IA (aged 36-68 years) were interviewed. The participants were employed full time, part time or on sick leave. From the analysis, a main theme 'Balancing work as a part of everyday life' and four sub-themes emerged: 1) Working despite challenges, 2) Prioritizing energy for work, 3) Fatigue affects everything and 4) Need for support. To be able to work was very important to all participants. In general, they were stretching their limits, had concerns about maintaining their job and they used different strategies to deal with the challenges they met at work. Flexibility at work in every possible way and support from employers and co-workers were the main needs to be able to remain at work

Conclusion: Overall, patients with IA prioritized to keep working, but experienced challenges with balancing their work and energy in everyday life. They need support and flexibility at work to be able to remain at work. REFERENCES:

[1] Sokka T, Kautiainen H, Pincus T, Verstappen SMM, Aggarwal A, Alten R, et al. Work disability remains a major problem in rheumatoid arthritis in the 2000s: Data from 32 countries in the QUEST-RA Study. Arthritis Research and Therapy. 2010;12(2):R42-R.

[2] Hansen SM, Hetland ML, Pedersen J, Ostergaard M, Rubak TS, Bjorner JB. Effect of rheumatoid arthritis on longterm sickness absence in 1994-2011: A danish cohort study. Journal of Rheumatology. 2016;43(4):707-15.

[3] Madsen CMT, Kjaer, S., Primdahl, J., Christensen, J. R., \& von Bulow, C. A SYSTEMATIC REVIEW OF JOB LOSS PREVENTION INTERVENTIONS FOR PERSONS WITH INFLAMMATORY ARTHRITIS. Annals of the rheumatic diseases, 79(Suppl 1) 916-917 [FRI0624-HPR]2020.

Disclosure of Interests: None declared

DOI: 10.1136/annrheumdis-2021-eular.1549

\section{OP0262-HPR THE NEURO-QOL UPPER EXTREMITY FUNCTION SCALE: NEW OPPORTUNITIES TO MORE RELIABLY AND PRECISELY MEASURE SELF-REPORTED HAND FUNCTION AND SELF-CARE ACTIVITIES IN PEOPLE WITH RA}

S. J. Bartlett ${ }^{1}$, O. Schieir ${ }^{2}$, M. F. Valois ${ }^{3}$, G. Boire ${ }^{4}$, J. Pope ${ }^{5}$, E. Keystone ${ }^{6}$, C. Thorne ${ }^{7}$, D. Tin $^{7}$, C. Hitchon ${ }^{8}$, L. Bessette ${ }^{9}$, G. Hazlewood ${ }^{10}$, V. Bykerk ${ }^{11}$ on behalf of CATCH Investigators. ${ }^{1}$ Mc Gill University \& McGill University Health Centre, Clinical Epidemiology \& Rheumatology, Montreal, Canada; 2.,.., Montreal, Canada; ${ }^{3}$ Mc Gill University, Clinical Epidemiology, Montreal, Canada; ${ }^{4}$ University of Sherbrooke, Rheumatology, Sherbrooke, Canada; ${ }^{5}$ Western University, Rheumatology, London, Canada; ${ }^{6}$ University of Toronto, Rheumatology, Toronto, Canada; ${ }^{7}$ The Arthritis Program, Rheumatology, Newmarket, Canada; ${ }^{8}$ University of Manitoba, Rheumatology, Winnipeg, Canada; ${ }^{9}$ Laval University, Rheumatology, Québec, Canada; ${ }^{10}$ University of Calgary, Rheumatology, Calgary, Canada; ${ }^{11}$ Hospital for Special Surgery, Rheumatology, New York, Canada

Background: RA is an inflammatory disease that results in pain and loss of function, especially in the hands and wrists. Brief self-assessment tools that can reliably and precisely quantify hand/wrist function are needed to assess inflammatory activity when a physical exam is not feasible and to capture day-to-day experience of living with RA. Neuro-QoL is part of the PROMIS family of self-report measures created using a patient-centred approach and IRT methodology. The Neuro-Qol Upper Extremity Function (UEF) scale measures ability across fine motor and ADLs involving digital, manual and reach-related function and self-care. Little is known about its performance in RA. 
Objectives: To evaluate the validity and responsiveness of the 8-item Neuro-QoL UEF in RA. We hypothesized scores would be strongly $(r>.70)$ associated with MHAQ, MD-HAQ, and PROMIS PF, moderately ( $r=.4$ to .7) to symptoms, disease activity, and QoL indicators, and be responsive to change in disease activity and PF.

Methods: Data were from the 0 and 6-month visits of adults with early RA (sx $<1$ yr) enrolled in the Canadian Early Arthritis Cohort, a prospective real-world study at 16 sites across Canada. Participants completed the Neuro-QoL UEF, MHAQ, MDHAQ, PROMIS-29, and PT Global at each visit. Rheumatologists recorded joint counts and MD Global. To evaluate content validity, we examined descriptive statistics across CDAl disease activity levels, and Pearson correlations between the Neuro-QOL UEF, legacy measures, CRP \& ESR. Responsiveness was assessed by correlating change scores from visits 0-6 between Neuro-QoL UEF disease activity and legacy PF scores.

Results: The 262 participants were mostly white $(83 \%)$ women $(71 \%)$ with a mean (SD) age of 55 (13). Summary statistics at 6-months are shown in Table 1. Neuro-QOL UEF was moderately-strongly correlated with MHAQ, MDHAQ, PROMIS-PF ( $|\mathrm{r}|=.63-.75)$ and moderately correlated with pain and stiffness, ( $|r|=.59,-.64)$, and CDAI, SDAI, PT\&MD Global, TJ \& SJ ( $|r|=.39-.58)$. Neuro-QOL UEF was moderately correlated with PROMIS QoL domains Pain, Fatigue, Anxiety, Depression, Sleep \& Participation ( $|r|=.39-.60)$

Table 1. Summary statistics of physical function and RA disease activity indices at 6 months.

\begin{tabular}{lcccccc}
\hline & Mean & SD & Mdn & $\mathbf{2 5 \%}$ & $\mathbf{7 5 \%}$ & (Min, Max) \\
\hline Physical Function & & & & & & \\
\hline Neuro-Qol UEF & 46.5 & 9.7 & 53.8 & 37.5 & 53.8 & $(21.8,53.8)$ \\
MHAQ (0-3) & 0.29 & 0.43 & 0.13 & 0.00 & 0.38 & $(0.00,2.25)$ \\
MD-HAQ (0-10) & 1.39 & 1.64 & 0.70 & 0.00 & 2.00 & $(0.00,8.00)$ \\
PROMIS-PF & 46.4 & 8.5 & 46.2 & 39.5 & 56.0 & $(23.3,56.0)$ \\
RA Disease Activity & & & & & & \\
CDAl & 9.3 & 9.9 & 6.0 & 3.0 & 13.0 & $(0.0,56.0)$ \\
SDAI & 10.7 & 10.9 & 6.8 & 3.1 & 15.2 & $(0.0,57.0)$ \\
Patient Global & 3.0 & 2.5 & 3 & 1 & 5 & $(0,10)$ \\
MD Global & 1.8 & 2.2 & 1 & 0 & 3 & $(0,9)$ \\
Swollen Joints (28) & 2.1 & 3.7 & 0 & 0 & 2 & $(0,20)$ \\
Tender Joints (28) & 2.4 & 3.9 & 1 & 0 & 3 & $(0,24)$ \\
\hline
\end{tabular}

Neuro-QOL scores decreased in a dose-response manner across worsening CDA DA states reflecting increasing impairment (Table 2). Persons with HDA reported the highest disability, scoring nearly 0.5 SD lower on the Neuro-QoL UEF than PROMIS PF. Change from baseline to 6 months in Neuro-QoL UEF was moderately correlated with changes in PROMIS PF, MHAQ, PT Global, and CDAI $(|r|=.44-.65)$. The mean change and range from 0-6 months in Neuro-QoL was significantly larger than in PROMIS (8.9 [95\% Cl 7.5, 10.4] vs. 5.4 [95\% Cl 4.4, 6.4])(see Figure).

Table 2. Mean scores $(95 \% \mathrm{Cl})$ at 6 months by CDAl level.

\begin{tabular}{lcccc}
\hline & REM & LDA & MDA & HAD \\
\hline NeuroQol UEF & $52.8(51.8,53.7)$ & $48.1(46.6,49.7)$ & $42.0(39.4,44.6)$ & $33.8(30.5,37.1)$ \\
MHAQ (0-3) & $0.05(0.02,0.09)$ & $0.19(0.14,0.24)$ & $0.45(0.34,0.57)$ & $0.90(0.63,1.17)$ \\
MD-HAQ (0-10) & $0.31(0.17,0.46)$ & $1.11(0.90,1.32)$ & $2.15(1.71,2.59)$ & $3.56(2.56,4.56)$ \\
PROMIS-PF & $52.8(51.4,54.2)$ & $46.8(45.3,48.2)$ & $42.3(40.4,44.2)$ & $38.0(34.4,41.6)$
\end{tabular}

Conclusion: Clinicians, researchers, and patients benefit from practical self-report tools that reliably and precisely monitor hand function in RA. Results offer initial evidence of validity and responsiveness and support use of Neuro-QoL UEF to self-assess inflammatory activity in the hands and day-to-day experiences of living with RA.

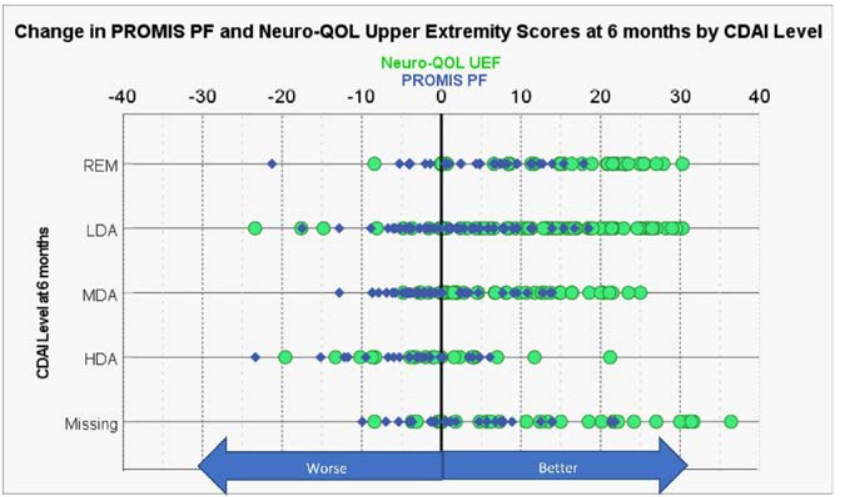

Acknowledgements: The CATCH study was designed and implemented by the investigators and financially supported through unrestricted research grants from: Amgen and Pfizer Canada - Founding sponsors since January 2007; AbbVie Corporation and Hoffmann-LaRoche since 2011; Medexus Inc. since 2013; Merck Canada since 2017, Sandoz Canada, Biopharmaceuticals since 2019, Gilead Sciences Canada since 2020 and Fresenius Kabi Canada Ltd. since 2021. Previously funded by Janssen Biotech from 2011-2016, UCB Canada and Bristol-Myers Squibb Canada from 2011-2018, Sanofi Genzyme from 2016-2017, and Eli Lilly Canada from 2016-2020.

Disclosure of Interests: None declared

DOI: 10.1136/annrheumdis-2021-eular.3259

\section{OP0263-HPR THE ROLE OF PHYSICAL EXERCISES IN REDUCING CHRONIC FATIGUE IN PATIENTS WITH RHEUMATOID ARTHRITIS}

A. Aleksandrov ${ }^{1,2}$, M. Nikitin ${ }^{3}, \underline{\text { V. Aleksandrov }}{ }^{1,2}$, N. Aleksandrova ${ }^{1} .{ }^{1}$ Federal State Budgetary Institution «Research Institute of Clinical and Experimental Rheumatology named after A.B. Zborovsky", Department of Functional Research Method, Volgograd, Russian Federation; ${ }^{2}$ Volgograd State Medical University, Department of Hospital Therapy, Volgograd, Russian Federation; ${ }^{3}$ FSB Institution "National Medical Research Center for Rehabilitation and Balneology" of the Ministry of Health of the Russian Federation, SanatoriumResort Complex "Vulan"- Scientific and Clinical Branch, Gelendzhik, Russian Federation

Background: Physical activity is an important non-pharmacological intervention that has a combination of biological, physical and psycho-social benefits and can positively influence chronic fatigue in patients with rheumatoid arthritis (RA) $[1,2,3]$.

Objectives: Evaluation of the effectiveness of the use of aerobic exercise (walking) to reduce fatigue in RA patients.

Methods: The study included 111 women with RA (mean age $54.4 \pm 11.03$ years old, mean duration of illness - $11.9 \pm 9.3$ years old). The DAS28-ESR indicator in RA patients was 2.84 [2.32; 3.05] points: low disease activity was diagnosed in $61.3 \%$ of patients, and remission in $38.7 \%$. The average level of fatigue according to the VAS screening scale was $71.6 \pm 8.93$ points. Fatigue was assessed using the Bristol Rheumatoid Arthritis Fatigue Numerical Rating Scale (BRAF-NRS V2). To assess the patient's tolerance to physical activity, a 6-minute walking distance (6MWD) test was used. A walking test at 50 meters was used to assess the functional state of patients in dynamics. The rehabilitation program (RP) of patients (for 21 days) included morning hygienic gymnastics, dosed walking (daily, duration 30-60 minutes) and walking in the air up to 3-3.5 hours a day. Vigorous movements "through pain" were contraindicated.

Results: No association was found between the duration of RA and all of the used numerical fatigue scales ( $p>0.05)$, but there was a weak positive relationship between VAS and NRS-overcoming with age $(r=0.21$ and $r=0.28)$. An association between DAS28-ESR and numerical fatigue scales VAS $(r=0.21)$, NRS effect $(r=0.25)$ and NRS - overcoming $(r=0.24)$ was found, despite the fact that this study did not include patients with moderate and high RA activity. There was a significant correlation between the walking time and the number of steps during the 50 -meter test $(r=0.6, p<0.001)$, as well as an association between the fatigue and the walking time $(r=0.33, p=0.001$ for VAS and $r=$ $0.41, p<0.001$ for NRS-severity) and the number of steps $(r=0.39, p<0.001$ fo VAS; $r=0.47, p<0.001$ for NRS-severity; $r=0.44, p<0.001$ for NRS-bridging)

Table 1. Dynamics of fatigue levels and physical indicators in RA patients

\begin{tabular}{lccc}
\hline & Before RP & In the end of RP & p \\
\hline VAS fatigue level & $71,2 \pm 9,08(71,5 ; 64-78)$ & $70,4 \pm 9,15(70 ; 64-78)$ & $p>0,05$ \\
BRAF-NRS: severity & $6,83 \pm 1,21(7 ; 6-8)$ & $6,51 \pm 1,18(7 ; 6-7)$ & $\mathrm{p}<0,01$ \\
BRAF-NRS: effect & $6,24 \pm 1,07(5 ; 4-6)$ & $5,95 \pm 1,08(6 ; 5-7)$ & $\mathrm{p}<0,05$ \\
BRAF-NRS: overcoming & $5,0 \pm 1,7(7 ; 6-8)$ & $7,76 \pm 1,37(5 ; 4-5)$ & $\mathrm{p}>0,05$ \\
50 meter test, number of steps & $79,3 \pm 8,64(78 ; 73-84)$ & $78,91 \pm 8,15(78 ; 73-83) \mathrm{p}>0,05$ \\
50-meter test, walking time, & $56,7 \pm 8,72(57 ; 50-63)$ & $55,9 \pm 8,59(56 ; 51-60)$ & $\mathrm{p}=0,01$ \\
$\quad$ seconds & &
\end{tabular}

* The data are presented as mean \pm standard deviation (median; interquartile range)After the completion of RP (Table), RA patients showed a significant reduction in the aspects of fatigue according to the NRS-severity $(Z=2.98, p=0.003)$ and NRS-effect $(Z=2.08, p=0.037)$ scales. There was also a decrease in the time spent by patients performing the $50 \mathrm{~m}$ walking test $(t=2.63, p=0.01)$, but the total number of steps did not change $(t=1.44, p=0.154)$. Fatigue and pain are important barriers to physical activity, but it is severe fatigue that reduces physical activity in patients with RA [4]. At the same time, physical activity itself can become a factor in reducing fatigue [5], including by reducing the activity of the disease [6].

Conclusion: The severity of fatigue in RA patients can be reduced by actively using non-pharmacological treatment strategies. Walking is a simple and effective solution to increase physical activity and it has a significant effect on fatigue in RA. 